\title{
Preventive Effects of Ginger Extract and Nigella sativa Oil on Anxiety and Depression Behavior in Wistar Rats Exposed to Mercuric Chloride
}

\author{
Sabri Benkermiche ${ }^{1}$, Samir Djemli ${ }^{1}{ }^{*}$, Meriem Haloui ${ }^{2}$, Mohamed Lamine Benabed ${ }^{1}$, Abdelkrim Tahraoui ${ }^{1}$
}

\section{Sabri Benkermiche1, Samir Djemli ${ }^{1, *}$, Meriem Haloui ${ }^{2}$, Mohamed Lamine Bena- bed $^{1}$, Abdelkrim Tahraoui ${ }^{1}$}

\section{'Applied Neuroendocrinology Laboratory, Department of Biology, Faculty of Sciences, Badji Mokhtar Annaba University, Annaba, ALGERIA. ${ }^{2}$ Department of Pharmacy, Faculty of Medicine, University of Batna 2, ALGERIA. \\ Correspondence \\ Samir Djemli \\ Applied Neuroendocrinology of Laboratory, Department of Biology, Faculty of Sciences, Badji Mokhtar Annaba University, ALGERIA. Email id: s_djemli@yahoo.fr \\ History \\ - Submission Date: 02-10-2021; \\ - Review completed: 29-10-2021; \\ - Accepted Date: 09-12-2021.}

DOI : 10.5530/pres.14.1.1

Article Available online http://www.phcogres.com

\section{Copyright}

(C) 2022 Phcog.Net. This is an openaccess article distributed under the terms of the Creative Commons Attribution 4.0

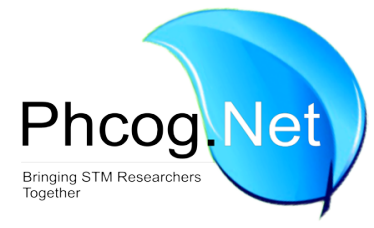

\begin{abstract}
Background: Mercuric chloride $\left(\mathrm{HgCl}_{2}\right)$ is toxic to humans and animals, and usually causes systemic and nerve damage. Aim: The aim of this study is to evaluate the neuro-protective effects of two medicinal plants rich in antioxidants against mercuric chloride poisoning in Wistar rats. Materials and Methods: This is an experimental study conducted on twenty-five adult rats randomly divided into five groups of five rats each, the untreated control group and the four groups are treated daily with Ginger extract $(500 \mathrm{mg} / \mathrm{kg} /$ day) and Nigella sativa oil $(2 \mathrm{ml} / \mathrm{kg} /$ day) for four weeks. The administration of mercuric chloride $(4 \mathrm{mg} / \mathrm{kg} /$ day) will be from the second week of experimentation to three weeks. Results: The results obtained showed by behavioral tests that the administration of inorganic mercury $\left(\mathrm{HgCl}_{2}\right)$ significantly increases the state of anxiety and depression of rats compared to control rats, while the groups pre-treated with antioxidants can reduce the damage of these behavioral disorders. Conclusion: Ginger extract and Nigella sativa oil have a very important role in neurobehavioral alterations induced by mercury toxicity.

Key words: Antioxidants, Mercuric Chloride, Anxiety, Depression, Neuroprotection, Wistar Rats.
\end{abstract}

\section{INTRODUCTION}

Mercury is one of toxic heavy metals. Due to industrial pollution and its deposition in ecosystems, mercury is a widespread pollutant ${ }^{[1]}$ Elemental form of mercury is a silver metal that exists as a viscous liquid at room temperature. Most people are familiar with the silver liquid in mercury thermometers. Mercury is a naturally occurring metal used in man-made products and processes, and is also emitted into the air from industrial sources. Human exposure to mercury comes from various sources, such as breathing mercury-containing air, using mercury-containing commercial products, and eating fish and seafood containing methylmercury ${ }^{[2]}$ Its exposure can be toxic to the kidneys, stomach and intestines and can also be embryotoxic, increasing rates of miscarriages and stillbirths, and can further increase blood pressure and is neurotoxic sometimes presenting with neuropsychiatric symptoms $s^{[3,4]}$ The toxicity of mercury can be prevented by using antioxidant defense mechanisms, including reducing or eliminating reactive oxygen species, free radicals, and heavy metals ${ }^{[5]}$ In herbal medicine, plant organs including: leaves, stems, roots, flowers, fruits and seeds are used as alternative and complementary therapies.
Some herbs with neuroprotective properties, including resveratrol, curcumin, ginsenosides, polyphenols, triptolide, etc ${ }^{[6]}$ One of this plantis the Zingiber officinale, has been used as a spice for over 2000 years. The high antioxidant activity of ginger is due to the polyphenolic 6-gingerol compounds and its derivatives contained in these roots. ${ }^{[7]}$ Another commonly used plant, Nigella sativa is a medicinal herb used for antioxidant activity. In rats, Nigella sativa seeds also play an important role in the lack of spatial cognition caused by chronic cerebral hypoperfusion. In addition, Nigella sativa's enhanced scopolamine promotes learning and memory deficits, and also reduces the AChE effect and oxidative stress in the mouse brain. The neuroprotective effects of Nigella and thymoquinone (TQ) on various neurological diseases such as Alzheimer's disease, epilepsy, and neurotoxicity have been studied in human and animal models. ${ }^{[8]}$

The aim of this study was designed to investigate the preventive effect of Nigella sativa oil and ginger extract in the improvement of anxious and depressive behavior of Wistar rats exposed to mercuric chloride $\left(\mathrm{HgCl}_{2}\right)$.
Cite this article: Benkermiche S, Djemli S, Haloui M, Benabed ML, Tahraoui A. Preventive Effects of Ginger Extract and Nigella sativa Oil on Anxiety and Depression Behavior in Wistar Rats Exposed to Mercuric Chloride. Pharmacog Res. 2022;14(1):1-4. 


\section{MATERIALS AND METHODS}

\section{Drugs}

Mercury II chloride $\left(\mathrm{HgCl}_{2}\right)$, Purity $\geq 99.5 \%$ and Ginger extract used in this research were obtained from (Sigma-Aldrich, St Louis, MO, USA), The Nigella sativa oil product by (CAP Pharm, Egypt).

\section{Animals and administration procedure}

Healthy male Wistar albino rats weighing $280 \pm 15 \mathrm{~g}$, obtained from the Pasteur Institute of Algiers, housed in standard polypropylene cages and maintained at an ambient temperature of $23 \pm 2^{\circ} \mathrm{C}$, a hygrometry of $45-55 \%$ and a natural photoperiod. The animals were divided at random into five groups of five animals each, the first group (T), control group, receives no treatment, the second group $(\mathrm{M})$ receives distilled water $(1 \mathrm{ml} / \mathrm{kg} /$ day) for one week (D01-D07) and mercuric chloride $(4 \mathrm{mg} / \mathrm{kg} / \mathrm{day})$ for three weeks (D08-D28), the third group $(G+M)$ receives ginger extract $(500 \mathrm{mg} / \mathrm{kg} /$ day) for four weeks (D1-D28) and mercuric chloride $(4 \mathrm{mg} / \mathrm{kg} /$ day) for three weeks (D08-D28) the fourth group $(\mathrm{N}+\mathrm{M})$ received Nigella sativa oil (2ml/kg/day) for four weeks (D1-D28) and mercuric chloride $(4 \mathrm{mg} / \mathrm{kg} /$ day) for three weeks (D08-D28) the fifth group $(\mathrm{G}+\mathrm{N}+\mathrm{M})$ received a ginger extract $(500 \mathrm{mg} / \mathrm{kg} /$ day $)$ and Nigella sativa oil $(2 \mathrm{ml} / \mathrm{kg} /$ day) during the whole experiment (D1-D28) and mercuric chloride $(4 \mathrm{mg} / \mathrm{kg} /$ day) for three weeks (D08-D28).All these treatments were administered by gastric gavage.

\section{Behavioral assessment}

\section{Open field test (OFT)}

The open field test (OFT) is designed to measure locomotion, exploration and anxiety in rats. The device consists of a base surrounded by Plexiglas parapets whose measures are respectively $70 \times 70 \times 40 \mathrm{~cm}$. The floor is in the form of squares of $10 \mathrm{~cm} \times 10 \mathrm{~cm}$ in diameter, it has been divided into two areas: central area and peripheral area to which each is $35 \mathrm{~cm}$ (Hall, 1934).

\section{Elevated plus-maze test (EPM)}

The elevated cross maze is used to measure the degree of anxiety in rodents. The labyrinth raised $50 \mathrm{~cm}$ from the ground is composed of four wooden Arms, two open arms $(50 \times 10 \mathrm{~cm})$ perpendicularly opposed to two closed arms $(50 \times 10 \mathrm{~cm})$ with $40 \mathrm{~cm}$ of plexiglass at the high edge. The intersection of the four arms (central platform) measures $10 \mathrm{~cm} .{ }^{[9]}$

\section{Forced swimming test (FST)}

The forced swimming test, or Porsolt test, is frequently used to examine depressive behavior ${ }^{[10]}$ The device for this test is aglass aquarium (height: $54 \mathrm{~cm}$; length: $34 \mathrm{~cm}$; width: $60 \mathrm{~cm}$ ) filled with water up to a height of $40 \mathrm{~cm}$ from which the rat does not use its lower limbs to stand on the surface or escape, thus subjecting it to forced swimming. The water is regularly maintained at $\left(24 \pm 1^{\circ} \mathrm{C}\right)$ and is renewed after each experimental session. ${ }^{[1]}$

\section{Statistical Analysis}

Statistical analysis of the data was performed with the software (GraphPad Prism 9.0.0). Data are presented as the mean \pm SEM (Standard Error of the Mean). All measured parameters were processed by a one-way analysis of variance (One-way ANOVA) and all these statistical analyses were followed by a post-hoc test (Dunnett's test) when a significant difference was determined.

\section{RESULTS}

\section{Anxiety tests \\ Open field test (OFT)}

The open field test is performed for $5 \mathrm{~min}$, on the $14^{\text {th }}$ day of experimentation, each animal is placed in the center of the device. Its displacement allows measuring the number of squares crossed as well as the number of rearing.

Statistical analysis of the results shows in Figure 1A a very highly significant decrease in the number of squares crossed by the groups (M; $34.00 \pm 1.14),(\mathrm{G}+\mathrm{M} ; 49.20 \pm 1.77),(\mathrm{N}+\mathrm{M} ; 42.00 \pm 1.51)$ and $(\mathrm{G}+\mathrm{N}+\mathrm{M}$; $39.80 \pm 3.65)$ compared to the control group ( $\mathrm{T} ; 68.60 \pm 2.50$ ). Therefore, a very highly significant increase in the $(\mathrm{G}+\mathrm{M} ; 49.20 \pm 1.77)$ group compared with the $(\mathrm{M} ; 34.00 \pm 1.14)$ group.

While in Figure 1B, the results reveal a highly significant decrease in the number of rearingin the group treated with mercuric chloride (M; 9.80 \pm 0.58$)$ and a significant decrease of the group $(\mathrm{G}+\mathrm{M} ; 12.00 \pm 1.22)$ compared to the control group $(\mathrm{T} ; 16.20 \pm 1.15)$ with significant and highly significant increases in the $(\mathrm{N}+\mathrm{M} ; 14.20 \pm 1.15)$ and $(\mathrm{G}+\mathrm{N}+\mathrm{M}$; $15.40 \pm 0.92)$ groups respectively compared to the $(M ; 9.80 \pm 0.58)$ group.

\section{Elevated plus-maze test (EPM)}

On the $21^{\text {st }}$ day of experimentation, each rat is placed for $5 \mathrm{~min}$ in the central area facing an open arm.

The results obtained in Figure 2A show very highly significant decreases in the $(M ; 22.40 \pm 0.92)$ and $(\mathrm{G}+\mathrm{N}+\mathrm{M} ; 32.40 \pm 2.65)$ groups and highly significant and significant decreases in the $(\mathrm{G}+\mathrm{M} ; 39.20 \pm 3.95),(\mathrm{N}+\mathrm{M}$; $42.60 \pm 1.74)$ groups in the time spent in the open arms compared to the control group (T; $54.80 \pm 4.54)$, as well as the $(\mathrm{G}+\mathrm{M} ; 39.20 \pm 3.95)$, $(\mathrm{N}+\mathrm{M} ; 42.60 \pm 1.74)$ groups represent highly significant and very highly significant increases in time spent in the open arms compared with the

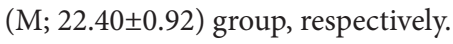

In Figure $2 \mathrm{~B}$, rats in the $(\mathrm{G}+\mathrm{M} ; 213.2 \pm 3.73),(\mathrm{N}+\mathrm{G} ; 237.4 \pm 2.67)$ groups show very highly significant decreases in the time spent in the closed arms

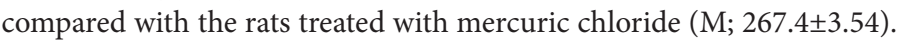
In contrast, we found a very highly significant and highly significant increase in the $(M ; 267.4 \pm 3.54)$ and $(G+N+M ; 258.6 \pm 2.89)$ group and a very highly significant decrease in the time spent in the closed arms

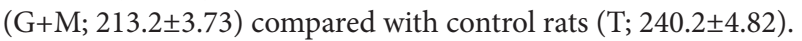
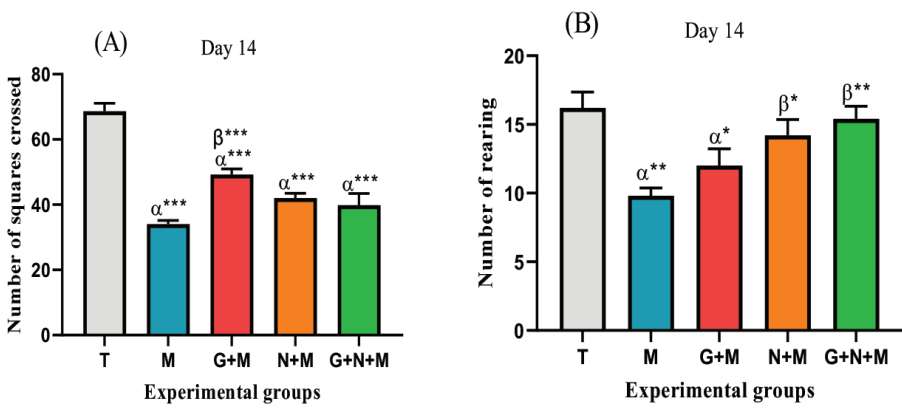

Figure 1: Anxiety-related behavior of rats in the open field test (OFT) on day 14 of the experiment $(n=05)$.

(A): Number of squares crossed; (B): Number of rearing

Significance was defined as a $p$-value less than $0.05\left({ }^{*} p<0.05 ;{ }^{* *} p<0.01\right.$; ${ }^{* * *} p<0.001$ )

a: Comparison with control group (T)

$\beta$ : Comparison with the group treated with mercuric chloride $\left(\mathrm{HgCl}_{2}\right)(\mathrm{M})$ 
(A)

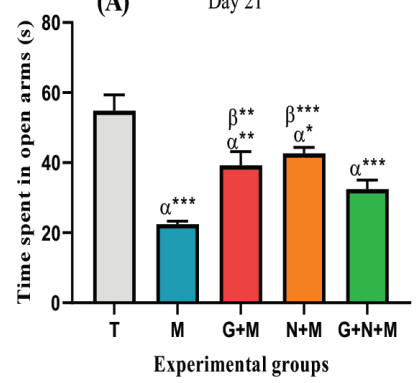

(B)

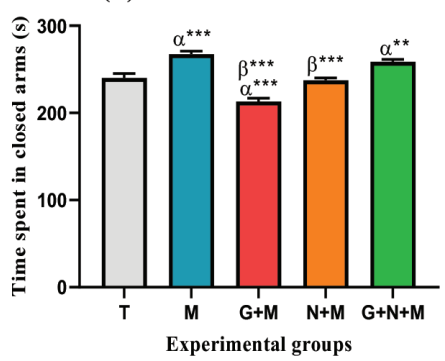

Figure 2: Anxiety-related behavior of rats in the elevated plus-maze test (EPM) on day 21 of experimentation $(n=05)$.

-(A): Time spent in open arms (s); -(B): Time spent in closed arms (s) Significancewas defined as a $p$-value less than $0.05\left({ }^{*} p<0.05 ;{ }^{* *} p<0.01\right.$; $\left.{ }^{* * *} p<0.001\right)$

a:Comparison with control group (T).

$\beta$ : Comparison with the group treated with mercuric chloride $\left(\mathrm{HgCl}_{2}\right)(\mathrm{M})$.

(A)

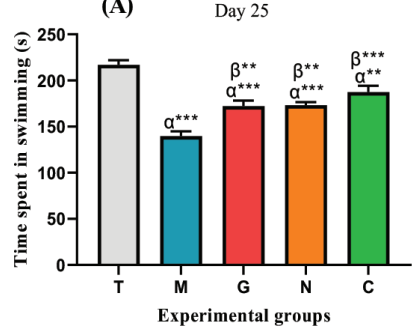

(B) Day 25

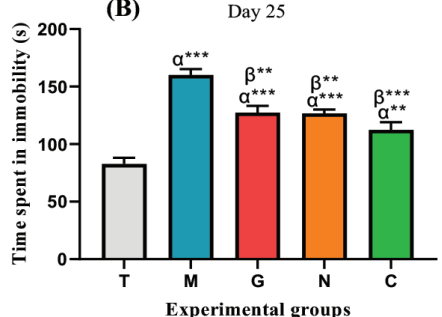

Figure 3: Depression-related behavior of rats in the forced swimming test (FST) on day 25 of the experiment ( $n=05)$.

(A): Time spent in swimming (s); (B): Time spent in immobility (s)

Significance was defined as a $p$-value less than $0.05\left({ }^{*} p<0.05 ;{ }^{* *} p<0.01\right.$;

${ }^{* * *} p<0.001$ )

a: Comparison with control group $(\mathrm{T})$.

$\beta$ : Comparison with the group treated with mercuric chloride $\left(\mathrm{HgCl}_{2}\right)(\mathrm{M})$.

\section{Depression test}

\section{Forced swimming test (FST)}

On the $24^{\text {th }}$ day of experimentation the rats are placed individually in the aquarium of the forced swimming test for $15 \mathrm{~min}$, this phase serves to induce a mental depression (depressant session), $24 \mathrm{hr}$ later $\left(25^{\text {th }}\right.$ day) a second session lasting 5 min was performed, during which, the times of immobility and swimming.

In this test, the time of swimming decreased very highly significantly in the rats of $(M ; 139.6 \pm 5.33),(G+M ; 172.2 \pm 6.11)$ and $(N+M ; 173.2 \pm 3.33)$ groups and highly significantly of $(\mathrm{G}+\mathrm{N}+\mathrm{M} ; 187.4 \pm 6.86)$ group compared to the control group ( $\mathrm{T} ; 217.0 \pm 5.07)$. Therefore, rats in the $(\mathrm{G}+\mathrm{M} ; 172.2 \pm 6.11),(\mathrm{N}+\mathrm{M} ; 173.2 \pm 3.33)(\mathrm{G}+\mathrm{N}+\mathrm{M} ; 187.4 \pm 6.86)$ groups had a longer swimming time than that of rats in the $(\mathrm{M} ; 139.6 \pm 5.33)$ group (Figure 3A).

In addition, the immobility time of rats was very highly significantly increased in the $(\mathrm{M} ; 160.0 \pm 5.16),(\mathrm{G}+\mathrm{M} ; 127.4 \pm 5.80)$, and $(\mathrm{N}+\mathrm{M}$; $126.8 \pm 3.33)$ groups and highly significantly increased in the $(\mathrm{G}+\mathrm{N}+\mathrm{M}$; $112.4 \pm 6.70$ ) group compared to the control group ( $\mathrm{T} ; 82.80 \pm 5.21$ ). In addition, immobility time was significantly shorter in the experimental groups compared with the $(M ; 160.0 \pm 5.16)$ group (Figure 3B).

\section{DISCUSSION}

In this study, a decrease in the number of squares crossed and the number of rearing was observed in the mercuric chloride groups compared to the control group in the open field test, as we observed that the rats treated with mercuric chloride spent more time in the closed arms and less time in the open arms compared to the control rats in the elevated plus-maze test, which means that the subchronic treatment with mercuric chloride $(4 \mathrm{mg} / \mathrm{kg})$ triggers a state of anxiety in these animals. This is consistent with the results found by ${ }^{[12]}$ where the results obtained in open field test (OFT) also indicate that mercury can cause anxiety because we measured an increase in the number of crossing squares and time at the periphery compared to activity and time at the center. In fact, the longer the time spent on the periphery of the open field, the higher the anxiety level. This indicates that the mice treated with mercuric chloride are more anxious than control animals in open field test. In this study, in addition to open field test (OFT), we also tested the anxiety effect of mercuric chloride on mice through other behavioral tests, such as the elevated plus-maze test (EPM), This is undoubtedly one of the most widely, used animal models in contemporary anxiety preclinical research ${ }^{[13]}$ In rats pretreated with ginger extract $(500 \mathrm{mg} / \mathrm{kg})$ and Nigella sativa oil $(2 \mathrm{ml} / \mathrm{kg})$, show significant increases in OFT variables were found to correspond to those in control rats. In the EPM test, rats a higher time spent on the open arms and a lower time in closed arms compared to rats treated with mercuric chloride. The effect of herbs in reducing depression and anxiety may be related to the effects of herbal ingredients ${ }^{[14]}$ Ginger extract exerts anti-anxiety effects in anxious behavior models, which may be caused by increased serotonin synthesis, and affects tryptophan metabolism and distribution in a manner similar to antidepressant drugs $^{[15]}$ Ginger and its active constituents may influence central nervous system5-HT metabolism and function by various actions, e.g., by enhancing its synthesis, decreasing its degradation or release and/or blocking its receptors ${ }^{[16]}$ We can conclude that ginger extract can reduce anxiety. ${ }^{[17]}$ There might have some decrease of anxiety due to the effect of Nigella sativa on several neurotransmitters-like 5-hydroxytryptamine (5-HT) and gamma amino butyrate (GABA). Accordingto Perveenetal., (2009) Nigella sativa increases the level of 5-HT and thus decrease anxiety. Thymoquinone in Nigella sativa might also decrease nitric oxide and reverse decreased brain GABA content and give anxiolytic effect ${ }^{[18]}$ Several studies indicate that anxiety and depressive disorders are not heterogeneous disorders, but rather share many common symptoms and pathogenic mechanisms ${ }^{[19]}$ Also, a number of studies have evaluated the effects of inorganic mercury in the central nervous system and reported the presence of behavioral dysfunctions, in particular the anxiety and depression ${ }^{[20,21]}$ In the current study, the forced swimming test (FST) indicates depressive behavior in rats treated with mercuric chloride. Pre-treatment with ginger extract and Nigella sativa alone and in combination enhanced swimming time, thereby reducing the immobility time in rats in FST, indicating antidepressant-like activity of this antioxidants. In depression studies, monoamine neurotransmitters such as serotonin (5- HT), noradrenaline (NA) and dopamine (DA) play an important role in mediating depressive behaviors. ${ }^{[22]}$ It has been well proven that swim/immobility influences serotonergic signaling in brain, resulting into increase synaptic transmission which ultimately leads to change in response from immobility to swimming and climbing in FST. ${ }^{[23]}$ Ginger is used for the treatment of various conditions, including atherosclerosis, migraine headaches, rheumatoid arthritis, high cholesterol, ulcers and depression. 6-gingerol, isolated from ginger rhizome oil affected neurotransmission in the snail and possessed neuroprotective effects in rodents. ${ }^{[24,25]}$ However, true mechanism of antidepressant effect of the Ginger is still unknown but behavioral parameters in forced swimming test confirmed potential 
antidepressant effect as serotonergic agents. ${ }^{[26,27]}$ The antidepressant effect of thymoquinone (active constituent of Nigella sativa) by increasing 5-HT concentrations which in turns modulate/down regulate the swim or hanging stress induced serotonergic dysfunction. The synaptic enhancement of monoamine level, predominantly 5 -HT, is the key pharmacological mechanism of the anti-depressant effect. In view of these results, it's suggested that ginger extract and Nigella sativa oil alone and in combination have powerful anxiolytic and antidepressant properties. $^{[28]}$

\section{CONCLUSION}

The present study demonstrated the adverse effects of mercuric chloride $\left(\mathrm{HgCl}_{2}\right)$ which induced anxiety and depression reflected in the decrease in the number of climbs and the number of squares crossed by rats in the open field test and an increase in time spent in the closed arms, On the other hand, a decrease in the time spent in the open arms in the elevated plus-maze test, and a higher significant difference in the period of swimming and immobility in rats treated with mercuric chloride compared to control rats in the forced swimming test. The pretreatment with ginger extract and Nigella sativa oil alone and in combination allowed to decrease the state of anxiety and depression of the rats as it is shown by the returns of the parameters of the behavioral tests to their normal levels close to the control rats, and exerts preventive effects against behavioral disorders induced by mercuric chloride and open an interesting research pathway to study the mechanisms of action of these antioxidants on neurobehavioral effects of toxic heavy metal.

\section{ACKNOWLEDGEMENT}

This research work was supported by research project $\mathrm{N}^{\circ}$ D01N01UN230120200003 funded by the Ministry of Higher Education Algeria. We wish to acknowledge Pr. Abdelkrim Tahraoui Applied Neuroendocrinology Laboratory, Department of Biology, University Badji Mokhtar, Annaba, Algeria for his help support and encouragement.

\section{CONFLICT OF INTEREST}

The authors declare that they have no conflict of interest.

\section{REFERENCES}

1. Dash HR, Das S. Bioremediation of mercury and the importance of bacteria mer genes. Int Biodeterior Biodegrad. 2012;75:207-13. doi: 10.1016/j. ibiod.2012.07.023.

2. Owoeye, OLATUN. D.E. Mattu, J. S., and Thomas, M. A. Afr J Biomed Res 2018. Bromocriptine and vitamin E were protective against mercury-induced purkinje neuron injury in male Wistar rats;21(2):193-9.

3. Chang F, Yeung KT, Chan G. Identifying Mercury heavy-metal poisoning masquerading as dementia and Parkinson's disease - Recognizing neuropsychiatric manifestations and dietary contributors. Can Geriatr Soc J CME. 2015;5(2):1-8

4. Xu J, Zhang J, Lv Y, Xu K, Lu S, Liu X, et al. Effect of soil mercury pollution on ginger (Zingiber officinale Roscoe): growth, product quality, health risks and silicon mitigation. Ecotoxicol Environ Saf. 2020;195:110472. doi: 10.1016/j. ecoenv.2020.110472.

5. Virmani A, Pinto L, Binienda Z, Ali S. Food, nutrigenomics, and neurodegeneration-neuroprotection by what you eat! Mol Neurobiol. 2013;48(2):353-62. doi: 10.1007/s12035-013-8498-3.

6. Stoilova I, Krastanov A, Stoyanova A, Denev P, Gargova S. Antioxidant activity of a ginger extract (Zingiber officinale). Food Chem. 2007;102(3):764-70. doi: 10.1016/j.foodchem.2006.06.023.

7. Abdolmaleki A, Akram M, Saeed MM, Asadi A, Kajkolah M. Herbal medicine as neuroprotective potential agent in human and animal models: a historical overview. J Pharm Care. 2020:75-82.

8. Montgomery KC. The relation on skip between fear induced by novel stimulation exploratory behaviour. J Comp Physio. 1955;48:254-60.

9. Roy V 2002. Contribution à l'étude de conduites émotionnelles chez le rat: Utilisation du handling postnatal et de l'approche éthoexpérimentale du comportement (Doctoral dissertation, Rouen).

10. Porsolt RD, Le Pichon M, Jalfre ML. Depression: A new animal model sensitive to antidepressant treatments. Nature. 1977;266(5604):730-2. doi: 10.1038/266730a0, PMID 559941

11. Molina-Hernández M, Tellez-Alcántara NP, García JP, Lopez JIO, Jaramillo MT. Synergistic interaction between ketoconazole and several antidepressant drugs with allopregnanolone treatments in ovariectomized Wistar rats forced to swim. Prog Neuropsychopharmacol Biol Psychiatry. 2004;28(8):1337-45. doi: 10.1016/j.pnpbp.2004.08.006, PMID 15588761.

12. Malqui $H$, Anarghou H, Ouardi FZ, Ouasmi N, Najimi M, Chigr F. Continuous exposure to inorganic mercury affects neurobehavioral and physiological parameters in mice. J Mol Neurosci. 2018;66(2):291-305. doi: 10.1007/s12031018-1176-1, PMID 30251082.

13. Rodgers RJ, Cole JC. The elevated plus-maze: pharmacology, methodology and ethology. Ethol Psychopharmacol. 1994:9-44.

14. Hogg S. A review of the validity and variability of the elevated plus-maze as an animal model of anxiety. Pharmacol Biochem Behav. 1996;54(1):21-30. doi: 10.1016/0091-3057(95)02126-4, PMID 8728535.

15. Kazemian A, Toghiani A, Shafiei K, Afshar H, Rafiei R, Memari M, et al. Evaluating the efficacy of mixture of Boswellia carterii, Zingiber officinale, and Achillea millefolium on severity of symptoms, anxiety, and depression in irritable bowel syndrome patients. J Res Med Sci. 2017;22:120. doi: 10.4103/ jrms.JRMS_905_16, PMID 29259631.

16. Bano S, Sharif $H$, Badawy AA. Effects of oral administration of an aqueous ginger extract on anxiety behavior and tryptophan and serotonin metabolism in the rat. Asian J Med Sci. 2021;12(6):38-43. doi: 10.3126/ajms.v12i6.34480.

17. Sedighi S, Nasiri B, Alipoor R, Moradi-kor N. 2017. Modulation of 6-gingerolin Antidepressant-like Effects: An Investigation of Serotonergic System in Mice Model. GMJ Medicine;1(1):21-6.

18. Fadaki F, Modaresi M, Sajjadian I. The effects of ginger extract and diazepam on anxiety reduction in animal model. Indian J Pharm Educ Res. 2017;51(3s):s159-62. doi: 10.5530/ijper.51.3s.4.

19. Gilhotra N, Dhingra D. Thymoquinone produced antianxiety-like effects in mice through modulation of GABA and NO levels. Pharmacol Rep. 2011;63(3):660-9. doi: 10.1016/s1734-1140(11)70577-1, PMID 21857076.

20. Zahn-Waxler C, Klimes-Dougan B, Slattery MJ. Internalizing problems of childhood and adolescence: Prospects, pitfalls, and progress in understanding the development of anxiety and depression. Dev Psychopathol. 2000;12(3):443-66. doi: 10.1017/S0954579400003102, PMID 11014747.

21. Peixoto NC, Roza T, Morsch VM, Pereira ME. Behavioral alterations induced by $\mathrm{HgCl}_{2}$ depend on the postnatal period of exposure. Int $\mathrm{J}$ Dev Neurosci. 2007;25(1):39-46. doi: 10.1016/j.ijdevneu.2006.11.002, PMID 17188452.

22. Mello-Carpes PB, Barros W, Borges S, Alves N, Rizzetti D, Peçanha FM, et al. Chronic exposure to low mercury chloride concentration induces object recognition and aversive memories deficits in rats. Int J Dev Neurosci. 2013;31(7):468-72. doi: 10.1016/j.ijdevneu.2013.05.009, PMID 23770019.

23. Hosseini SE, Hosseini SA. The therapeutic effects of medicinal plants on depression and anxiety disorders. Rep Health Care. 2018;4(1):67-80.

24. Borsini $F$. Role of the serotonergic system in the forced swimming test. Neurosci Biobehav Rev. 1995;19(3):377-95. doi: 10.1016/0149-7634(94)00050-b, PMID 7566740 .

25. Qiang LQ, Wang CP, Wang FM, Pan $Y, Y i$ LT, Zhang $X$, et al. Combined administration of the mixture of honokiol and magnolol and ginger oil evokes antidepressant-like synergism in rats. Arch Pharm Res. 2009;32(9):1281-92. doi: 10.1007/s12272-009-1914-6, PMID 19784585.

26. Liang MH. From America: Cookbook medicine or food for thought: Practice guidelines development in the USA. Ann Rheum Dis. 1992;51(11):1257-8. doi: 10.1136/ard.51.11.1257, PMID 1466606.

27. Khaki A, Farnam A, Rouhani S, Imantalab B, Seery S. Androgenic activity evaluation of ginger rhizome in reducing depression in the forced swimming test of rats Exposed to Electromagnetic Field (EMF); 2013.

28. Aquib M, Najmi AK, Akhtar M. Antidepressant effect of thymoquinone in animal models of depression. Drug Res. 2015;65(9):490-4. doi: 10.1055/s-00341389920, PMID 25207705.

Cite this article: Benkermiche S, Djemli S, Haloui M, Benabed ML, Tahraoui A. Preventive Effects of Ginger Extract and Nigella sativa Oil on Anxiety and Depression Behavior in Wistar Rats Exposed to Mercuric Chloride. Pharmacog Res. 2022;14(1):1-4. 